\section{DEVELOPMENT AND SENSITIVITY ANALYSIS OF AN ONLINE TOOL FOR EVALUATING DRAINAGE WATER RECYCLING DECISIONS}

\author{
B. D. Reinhart, J. R. Frankenberger, C. H. Hay, L. C. Bowling, B. G. Hancock
}

Beyond 2020,

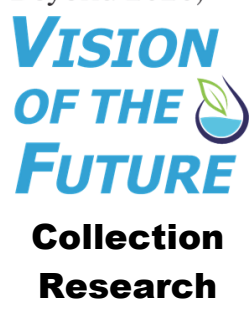

\begin{abstract}
HighLIGHTS
- A modeling framework for drainage water recycling (DWR) was developed to estimate irrigation and water quality benefits.

- Global sensitivity analysis was used to identify most and least influential input parameters affecting model outputs.

- Parameters controlling total available water had the most influence on applied irrigation and captured tile drain flow.

- The modeling framework and sensitivity results were used to develop an open-source, online tool for evaluating DWR.
\end{abstract}

\begin{abstract}
The U.S. Midwest is experiencing growth in both irrigation and subsurface (tile) drainage. Capturing, storing, and reusing tile drain water, a practice called drainage water recycling (DWR), represents a strategy for supporting supplemental irrigation while also reducing nutrient loads in tile-drained landscapes. This article describes the development and testing of an open-source online tool, Evaluating Drainage Water Recycling Decisions (EDWRD), which integrates soil and reservoir water balances for a tile-drained field and estimates potential benefits of DWR systems across multiple reservoir sizes. Irrigation benefits are quantified by applied irrigation and its relation to the irrigation demand, while water quality benefits are quantified by the amount and percentage of tile drain flow captured by the reservoir. Global sensitivity analysis identified input parameters affecting total available water as the most influential factors in estimating outputs. Initial and mid-season crop coefficients, irrigation management, and reservoir seepage rates were also influential. Curve number, fraction of wetted surface during irrigation, crop coefficients for the end of crop growth and frozen soil conditions, and the non-growing season residue amount were identified as low-sensitivity parameters. Results from the sensitivity analysis were used to prioritize and simplify user interaction with the tool. EDWRD represents the first open-source tool capable of evaluating DWR systems and can be used by multiple user groups to estimate the potential irrigation and water quality benefits of this innovative practice.
\end{abstract}

Keywords. Drainage water recycling, Dual crop coefficient, Open-source model, Sensitivity analysis, Subsurface drainage, Supplemental irrigation.

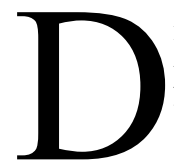
rainage water recycling (DWR) is an innovative practice for tile-drained landscapes that combines the crop production benefits resulting from drainage and supplemental irrigation with the water quality benefit of capturing and storing drained water and nutrients (Frankenberger et al., 2017; Reinhart et al., 2019). Ini-

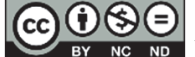

The authors have paid for open access for this article. This work is licensed under a Creative Commons AttributionNonCommercial-NoDerivatives 4.0 International License https://creative commons.org/licenses/by-nc-nd/4.0/

Submitted for review in January 2020 as manuscript number NRES 13900; approved for publication as a Research Article and as part of the National Irrigation Symposium 2020 Collection by the Natural Resources \& Environmental Systems Community of ASABE in April 2020.

The authors are Benjamin D. Reinhart, Senior Research Administration Specialist, and Jane R. Frankenberger, Professor, Department of Agricultural and Biological Engineering, Purdue University, West Lafayette, Indiana; Christopher H. Hay, Senior Manager, Production Systems Innovation, Iowa Soybean Association, Ankeny, Iowa; Laura C. Bowling, Professor, Department of Agronomy, and Benjamin G. Hancock, Staff Programmer, Department of Agricultural and Biological Engineering, Purdue University, West Lafayette, Indiana. Corresponding author: Benjamin Reinhart, 225 South University Street, West Lafayette, IN 47907-2093; phone: 765-496-6331; e-mail: breinhar@purdue.edu.
}

tial research of DWR systems has shown potential increases in yield for corn and soybeans of $40 \%$ or more during years with relatively dry growing seasons, provided that adequate water supplies are available within the DWR reservoir (Allred et al., 2014a; Melvin and Kanwar, 1995; Tan et al., 2007). DWR systems have also reduced nitrate loads by $27 \%$ to $41 \%$ and total dissolved phosphorus by $36 \%$ (Allred et al., 2014b; Tan and Zhang, 2011). While the potential for DWR to improve both crop production and water quality performance of tile-drained fields has been demonstrated, more widespread and longer-duration evaluations are needed to better understand the potential impact of the practice.

Models are one way to help evaluate the potential performance, under variable conditions and durations, of practices such as DWR that have yet to be widely adopted. Previous models have been developed to evaluate systems that include a field and irrigation reservoir, but their suitability as a tool for evaluating DWR systems is limited. Palmer et al. (1982) developed a field-scale model, and Arnold and Stockle (1991) developed a basin-scale model to simulate supple- 
mental irrigation from water storage reservoirs by combining existing crop and hydrology models. The Soil-Plant-AirWater (SPAW) model (Saxton and Willey, 2005) is a wellknown model that combines connected daily water balance routines for a field and reservoir, and it has been used as a tool in designing and evaluating agricultural wetland and pond systems (Andersen et al., 2010; Millhollon et al., 2009). The Pond Irrigation Model is an example of a more recent model that provides the ability to estimate water availability within an irrigation pond and crop irrigation demands simultaneously (Ouyang et al., 2018). However, none of these models include specific representations of tile drain flow or nutrient loads, which are necessary to describe the water quality benefits of DWR systems. In addition, when the water table is below the defined soil layer, these models do not account for the contribution of an upward flux of water from a shallow water table to the soil water balance, which can be an important contributor of water in the poorly drained soils of the U.S. Midwest (Stuff and Dale, 1978).

Model accessibility is another important consideration in maximizing the potential value of a model as a decision tool. Open-source software has become increasingly common in the development of decision tools for agriculture (de Wit et al., 2019; Foster et al., 2017; Jones et al., 2003) and can provide multiple benefits, such as improved scalability, accessibility, transparency, and reproducibility of these tools and their applications (Holzworth et al., 2014; Ince et al., 2012). The delivery of tools through online, web-based applications can also further increase accessibility and user interaction (Biehl et al., 2017; Han et al., 2012).

One of the challenges of using models in decision-making is parameter uncertainty. Some input parameters cannot be estimated accurately or precisely, and others can only be measured with difficulty and high expense. Sensitivity analysis is one approach to better understand and quantify which input parameters are most influential in determining model outputs (Pianosi et al., 2016). Local sensitivity analysis methods evaluate the influence of changes in individual input parameters on model outputs and can be effective in prioritizing influential factors within the model. However, local sensitivity analysis methods do not account for interaction effects among multiple input parameters and rely on the assumption that the model is linear (Cariboni et al., 2007). Global sensitivity methods move beyond these limitations to evaluate parameter influence across a multi-parameter input space. In this way, global sensitivity analysis methods can quantify interaction effects among input parameters and serve multiple purposes, including ranking input parameters by their relative influence, identifying non-influential or low-sensitivity input parameters, and characterizing regions of the multi-parameter input space that result in target model output values. In the case of identifying non-influential or low-sensitivity input parameters, global sensitivity analysis may be used in developing more parsimonious models (Saltelli et al., 2008).

In order to advance understanding of DWR systems and aid users in evaluating potential locations for practice suitability, there is a need for an open modeling framework and tool capable of simulating the entire DWR system under var- ious settings. The objectives of this study were to: (1) describe a modeling framework to simulate the field and reservoir water balance of DWR systems, (2) conduct a global sensitivity analysis to determine influential and low-sensitivity input parameters to better understand the potential variability in model outputs, and (3) develop an openly distributed online tool for evaluating DWR systems in applied settings. The resulting open-source framework provides a foundation for modeling DWR systems and advances understanding of the potential benefits of this novel practice.

\section{MATERIALS AND MethodS \\ Modeling Drainage WATER RECYCling}

The model was based on the framework developed by Reinhart et al. (2019), who applied it for two tile-drained sites with measured tile drain flow, soil, and weather data. This modeling framework consisted of interconnected water balances to a cropped field and a drainage water storage reservoir (fig. 1).

The field component of the DWR system was described by the drained area that provides tile drainage to the reservoir, the irrigated area that receives irrigation from the reservoir, and the crop being simulated. Surface runoff was estimated based on the USDA-NRCS curve number approach (Allen et al., 2007; USDA-NRCS, 2004). Crop evapotranspiration (ET) was calculated using the FAO-56 dual crop coefficient approach, allowing for soil water stress conditions (Allen et al., 1998). Basal crop coefficient values were climate-corrected for local conditions based on monthly values for wind speed and minimum relative humidity. The soil water control volume, extending from the soil surface to the tile drain depth, was defined as the zone in which crops may access and use water through transpiration processes. The total amount of crop-available water that could be held within this control volume was described as the difference in water contents between field capacity and wilting point, averaged across the depth of the control volume.

An impermeable layer is common in the poorly drained soils of the U.S. Midwest and can result in a perched, shallow water table that provides a source of water flow into the overlying soil layers (Stuff and Dale, 1978). To account for this contribution, an upward flux of water from a shallow water table was added to the soil water balance during periods of soil water deficit when the water table is below the level defined by the soil water control volume. The total amount of upward flux was set less than or equal to the maximum potential upward flux, based on the water table position and soil type, or the daily soil water deficit amount, whichever is less. The maximum potential upward flux was determined from relationships of water table and upward flux developed using the soil utility module in DRAINMOD (Reinhart et al., 2019; Skaggs et al., 2012).

Evaporation and transpiration during the non-growing season were divided into four stages: post-harvest, frozen, thaw, and pre-plant. The post-harvest period was defined as the period extending from harvest to the typical soil freeze date, and the pre-plant period was defined as the period between the start of preparatory tillage activities and crop 


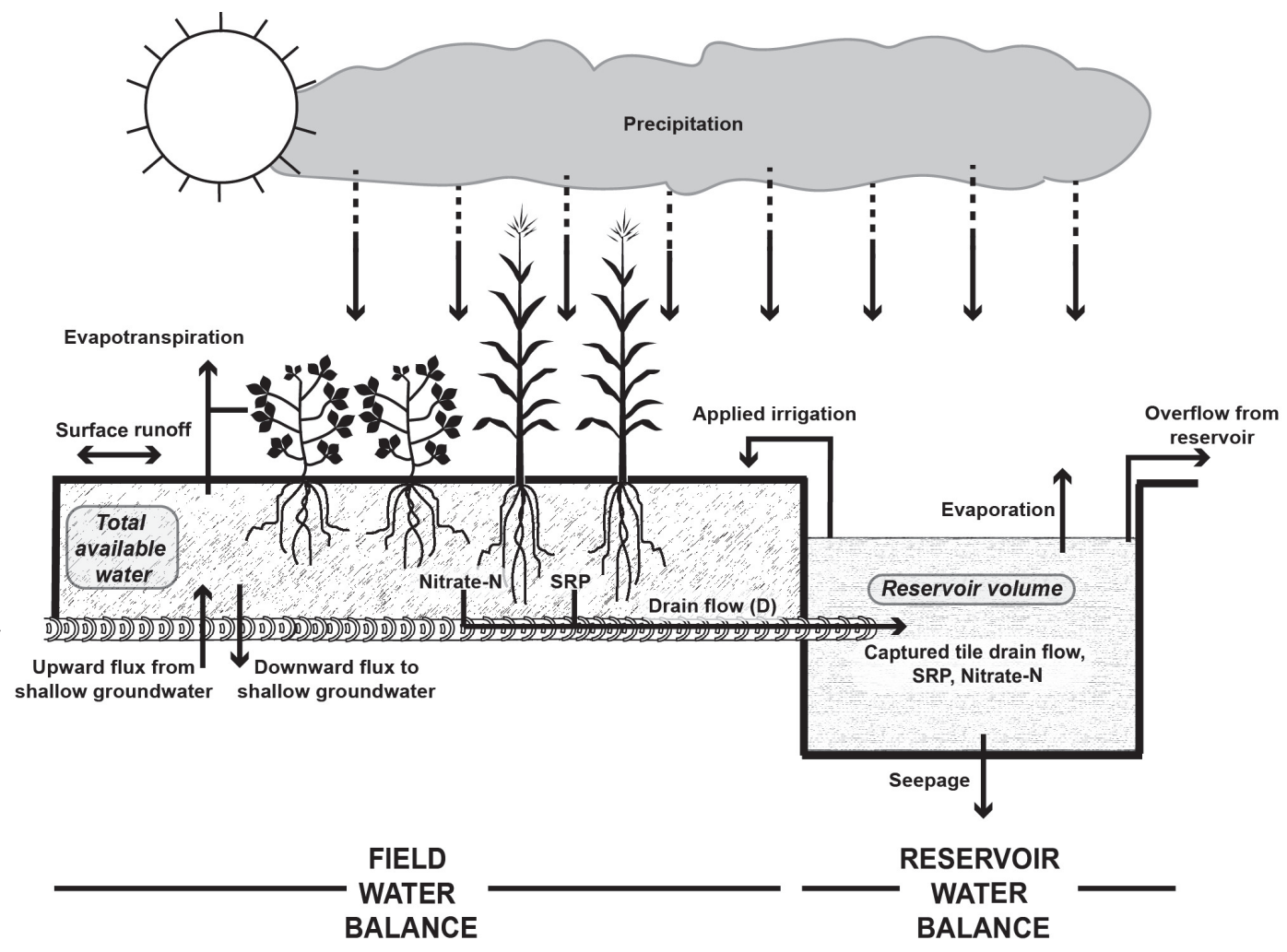

Figure 1. Modeling framework of the drainage water recycling system.

planting date. During the post-harvest and thaw stages, the basal crop coefficient value was set to 0.0 to reflect a lack of a growing crop, and the fraction of the soil surface exposed to evaporation was set to 1.0 to account for a fully exposed surface for evaporation. The total amount of evaporable water was reduced by $0.5 \%$ for each percent of residue cover to reflect increased moisture retention from crop residue. These limitations on total evaporable water were removed during the pre-plant stage. During the frozen stage, a single average coefficient value was used to estimate evaporative losses (Hay and Irmak, 2009).

The reservoir component of the DWR system was described by a maximum reservoir storage capacity calculated based on the average water depth and surface area when the reservoir is completely full. The reservoir is supplied with water through daily precipitation and tile drainage, and each are stored and later used as an irrigation water supply for the field. Measures of open water evaporation were required to estimate the amount of water evaporating from the reservoir water surface. Seepage losses from the reservoir were assumed to be constant based on an average daily rate of reservoir seepage. Nutrient concentration data for dissolved constituents that travel with tile drain flow, such as nitrate and soluble reactive phosphorus, were combined with tile drain flow to calculate the associated nutrient loads in the drainage water. Daily tile drain flow and nutrient loads were recorded as captured by the reservoir whenever reservoir water storage capacity is available or discharged through overflow whenever the reservoir exceeds maximum capacity.

All model input data and parameters for the field and reservoir water balance and water quality calculations in the model are listed in table 1. Default values may be used for many of these, and sensitivity analysis was conducted to determine which input parameters were least influential in affecting model outputs, making the use of default values appropriate.

The model provides daily soil and reservoir water balance outputs across multiple reservoir sizes (table 2). Two annual

Table 1. Input data and parameters for water balance and water quality calculations.

\begin{tabular}{|c|c|c|}
\hline Daily time-series data & & $\begin{array}{l}\text { Precipitation, reference evapotranspiration, open water evaporation, tile drain flow, nutrient concentrations, and } \\
\text { water table depth. }\end{array}$ \\
\hline \multirow[t]{5}{*}{ Input parameters } & Weather & $\begin{array}{l}\text { Monthly average wind speed, monthly average minimum relative humidity, and average crop coefficient for } \\
\text { frozen conditions. }\end{array}$ \\
\hline & Reservoir & Average reservoir surface area and depth, and daily rate of reservoir seepage. \\
\hline & Soil & $\begin{array}{l}\text { Runoff curve number, soil water control volume }{ }^{[a]} \text {, evaporation layer depth, field capacity and wilting point of } \\
\text { soil water control volume and evaporation layers, and readily evaporable water. }\end{array}$ \\
\hline & Crop & $\begin{array}{l}\text { Crop type, planting date, length of crop stages and non-growing season periods, basal crop coefficients and crop } \\
\text { heights for each crop stage, and water depletion fraction. }\end{array}$ \\
\hline & Field & $\begin{array}{l}\text { Drained and irrigated field area, irrigation application depth, fraction of surface wetted by irrigation, non-grow- } \\
\text { ing season residue amount. }\end{array}$ \\
\hline
\end{tabular}


Table 2. Daily and annual calculated outputs for the model.

\begin{tabular}{cc}
$\begin{array}{c}\text { Soil water balance } \\
\text { (depth units) }\end{array}$ & $\begin{array}{c}\text { Precipitation, applied irrigation, upward flux from the water table into the soil water control volume, runoff, po- } \\
\text { tential crop evapotranspiration, actual crop evapotranspiration, tile drain flow, and soil water. }\end{array}$ \\
\hline $\begin{array}{c}\text { Reservoir water balance } \\
\text { (volumetric units) }\end{array}$ & $\begin{array}{c}\text { Precipitation, tile drain flow, tile drain nutrient load, runoff, irrigation withdrawal, seepage, surface evaporation, } \\
\text { overflow, captured tile drain flow, captured tile drain nutrient load, and water level depth. }\end{array}$ \\
\hline Annual metrics & $\begin{array}{c}\text { Annual applied irrigation, annual relative irrigation supply, percent tile drain flow reduction, and percent tile } \\
\text { drain nutrient load reduction. }\end{array}$ \\
\hline
\end{tabular}

metrics were calculated to evaluate the irrigation performance of the DWR system: annual applied irrigation and annual relative irrigation supply (ARIS; Malano and Burton, 2001). ARIS was calculated for the DWR system as the annual applied irrigation from a given reservoir size divided by the amount of irrigation that would be applied given an unlimited water supply. Water quality performance of the DWR system was evaluated based on the absolute and percent tile drain flow and nutrient load reductions. Percent reductions were calculated as the amount of tile drain flow or nutrient load that was captured by a given reservoir size divided by the total amount of flow or nutrients that were delivered through the tile drains.

\section{Sensitivity ANALYSIS}

A sensitivity analysis was conducted to achieve two goals. The first goal was to compare the influence of uncertainty in model input parameters on the overall uncertainty in the estimated outputs of applied irrigation and captured tile drain flow volume. By prioritizing which input parameters create the most variability in model outputs, user interaction within an online tool may be focused on the parameters that are most important in obtaining reliable results. The second goal was to identify any input parameters that have minimal effect on model outputs across their range of potential values and may therefore be set with default values in the model. User interactions with the tool can then become more focused by emphasizing influential input parameters and deemphasizing low-sensitivity parameters within the user interface. These goals can be referred to as factor prioritization and factor fixing (Saltelli et al., 2008; Sobol, 2001).
A variance-based global sensitivity analysis method was chosen to avoid any assumptions related to model linearity or additivity. Sobol's method (Sobol, 2001), as implemented in the open-source Python package SALib (Herman and Usher, 2017), was used to explore first-order and total-order sensitivities across 13 field, soil, crop, and reservoir input parameters (table 3). Input parameters such as reservoir and field sizes, crop planting and growth dates, and daily timeseries data were not included in the sensitivity analysis as they are expected to be known values for a specific site and crop being simulated by a user, or reasonably obtainable from previously published resources or literature (e.g., Abendroth et al., 2017; Christianson and Harmel, 2015; Hertzberger et al., 2019). Minimum and maximum values were assigned for each input parameter included in the sensitivity analysis using standard references described by the following. Curve number and reservoir seepage values were assigned based on USDA-NRCS engineering standards (USDA-NRCS, 2004, 2009). Values for the growing season crop coefficients, water depletion fraction, soil water control volume and soil evaporation zone, readily evaporable water, and fraction of wetted surface were based on Allen et al. (1998).

Water storage in the soil profile, both as plant-available water and total evaporable water, is a key component of the soil water balance. Plant-available water and total evaporable water are defined by four input parameters: soil water control volume, soil evaporation zone depth, and water contents at field capacity and wilting point. Sensitivity of model outputs to any of these input parameters represents sensitiv-

Table 3. Input parameters used in model sensitivity analysis.

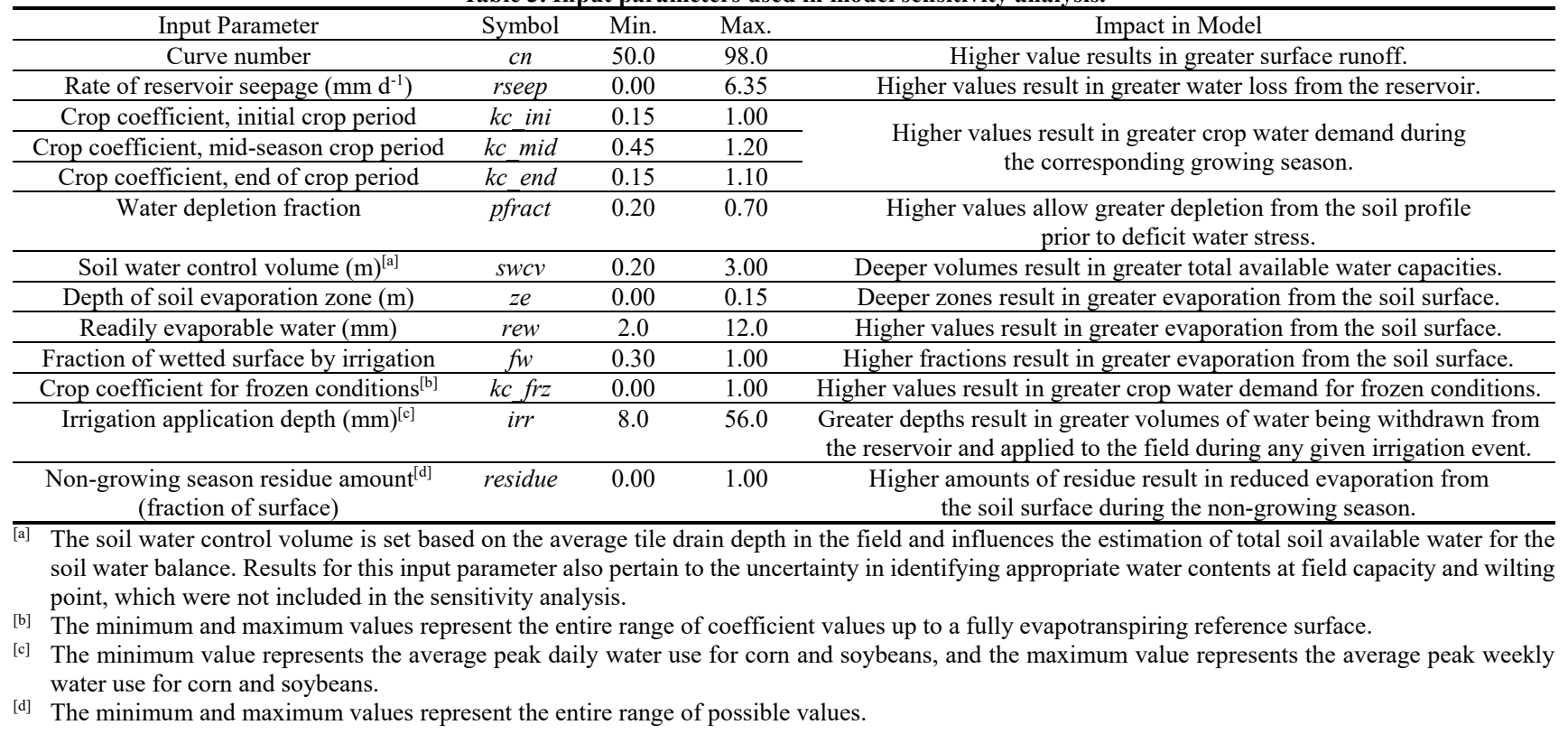


ity to changes in the total plant-available water or total evaporable water for the corresponding water balances. To reduce the total number of input parameters included in the sensitivity analysis, we chose to vary only two of the input parameters, soil water control volume and soil evaporation zone depth, while keeping the water contents at field capacity and wilting point fixed. However, variation in the field capacity and wilting point water contents would have the same effect in defining the soil profile water storage.

Time-series data for the sensitivity analysis were obtained from a tile-drained site in east-central Indiana (Reinhart et al., 2019; Saadat et al., 2018). The 2007 calendar year was used and had an annual precipitation amount of $970 \mathrm{~mm}$. This was nearly equal to the 30 -year normal annual precipitation, but only $36 \%$ of the annual precipitation occurred between May and September, which indicated drier than average growing season conditions. Because time-series data were not included in the sensitivity analysis, results should be taken within the context of this site, and results may vary given significantly different climate conditions. Considering that there are currently no recommendations for the ideal reservoir size for this practice, and the ideal reservoir size will vary depending on the goals of a potential adopter, multiple reservoir sizes representing $2 \%, 4 \%, 6 \%, 8 \%$, and $10 \%$ of the irrigated field area were simulated to evaluate any changes in sensitivity due to varying levels of water storage. For all reservoir sizes, the average depth was assumed to be $3.05 \mathrm{~m}$.

No prior knowledge of underlying distributions or correlations were available for the input parameters used in this analysis, as many are not easily measured or widely reported in the literature. Inputs were assumed to follow a uniform distribution and were randomly sampled from this distribution to ensure independence among inputs using the Saltelli extension of the Sobol sequence (Saltelli, 2002). The assumption of equal probability across the input range is common for unknown input parameters (DeJonge et al., 2012; Muleta and Nicklow, 2005), and provided that the input ranges are based on the best available knowledge, the ultimate assignment of a specific probability distribution function should have minimal effects on the analysis (Hann et al., 1998).

First-order sensitivity values describe the individual effect of an input parameter on the overall variance of the output and provide an appropriate measure for factor prioritization (eq. 1):

$$
S_{x, i}=V\left(E\left(Y \mid X_{i}\right)\right) / V(Y)
$$

where $S_{x, i}$ is the first-order sensitivity of input parameter $X_{i}$, $E\left(Y \mid X_{i}\right)$ is the conditional expectation of output $Y$ when $X_{i}$ is fixed, $V\left(E\left(Y \mid X_{i}\right)\right)$ is the variance in the conditional expectation taken across all values of $X_{i}$, and $V(Y)$ is the unconditional variance in output $Y$ across all input parameters. When the variance in the conditional expectation is large, this indicates that input parameter $X_{i}$ shows a large contribution to the overall variance in the output and suggests that $X_{i}$ is an influential input parameter.
The total-order sensitivity includes the first-order sensitivity as well as all interactions among higher-order combinations of input parameters (eq. 2):

$$
S_{T, x i}=E\left(V\left(Y \mid X_{\sim i}\right)\right) / V(Y)
$$

where $S_{T, x i}$ is the total-order sensitivity of input parameter $X_{i}$, $V\left(Y \mid X_{\sim i}\right)$ is the conditional variance of output $Y$ when all parameters excluding $X_{i}$ (i.e., $\left.X_{\sim i}\right)$ are fixed, $E\left(V\left(Y \mid X_{\sim i}\right)\right.$ ) is the average value of the conditional variance taken across all parameters except $X_{i}$. If this average value is small, this indicates that input parameter $X_{i}$, either individually or through a higher-order combination of parameters, contributes minimally to the overall variance in the output and suggests that $X_{i}$ is insensitive with respect to $Y$. Because total-order sensitivity values capture both the influence of an individual input parameter and its interaction effects, total-order sensitivity measures are more appropriate for the goal of factor fixing.

All first-order and total-order sensitivity values range from 0.0 to 1.0 , with values closer to 1.0 indicating more influential input parameters or higher levels of interaction involving the input parameter. Because the goal of factor fixing in this study was to simplify user interaction with the online tool, a relatively high screening threshold of 0.05 for total-order sensitivity was used to identify input parameters as candidates for simplification. The result of using this high screening threshold led to a set of input parameters with low sensitivity, as opposed to identifying completely insensitive input parameters (Sarrazin et al., 2016).

Estimated first-order and total-order sensitivity values were tested across multiple sample sizes $(N=[1,000 ; 2,000$; $4,000 ; 8,000 ; 17,500])$ to evaluate for convergence and stability in input parameter ranking. A maximum sample size of 17,500 was chosen based on results from Sarrazin et al. (2016), which showed convergence at this sample size for a model with a similar number of inputs when evaluating input parameter sensitivity for the purpose of parameter ranking and screening. Convergence of estimated values for first-order and total-order sensitivity was assessed based on the width of $95 \%$ confidence intervals. Sensitivity values were considered to have converged given confidence intervals less than or equal to 0.05 (Sarrazin et al., 2016). Convergence of input parameter ranking was evaluated qualitatively based on rank plots across each sample size to visually evaluate the extent of rank reversals across the set of input parameters (rank $1=$ most sensitive input parameter, rank $13=$ least sensitive input parameters). Input parameter rank was considered to have converged given no rank reversals among input parameters with sensitivity values greater than the screening threshold of 0.05 .

The tests for convergence and rank stability showed that a sample size of 17,500 was sufficient to meet the sensitivity analysis goals of prioritizing inputs and determining candidates for fixing. Results of this analysis for each reservoir size are provided as supplementary material (available at https://doi.org/10.6084/m9.figshare.11639679).

\section{ONLINE TOOL}

The algorithms were developed into an online tool called Evaluating Drainage Water Recycling Decisions (EDWRD; 
https://transformingdrainage.org/tools/edwrd). EDWRD is an open-source model that allows users to simulate the potential benefits of DWR systems across a range of field and reservoir settings. The source code for EDWRD can be found at https://github.com/TransformingDrainageProject/edwrd.

EDWRD is hosted on a virtual Linux server. The tool user interface was developed using JavaScript libraries, and a backend Javascript runtime environment is used to process submitted input form and location data. Python 3.7 scripts handle location information to identify average climate conditions (e.g., wind speed, relative humidity, soil freeze/thaw dates) from nearby NOAA weather stations. These climate and input form data are parsed and passed to an additional script that executes the model algorithms. Output from the script is routed back through the server to the client application where model results and graphs are provided. Graphs were developed using the Google charts web service.

\section{RESULTS AND DISCUSSION MODEL OUTPUTS AND VARIABILITY}

Across the sampled input parameter values, the impact of DWR on applied irrigation and captured drain flow vary widely, even for one site and a single year (fig. 2). Violin plots were generated using the Matplotlib library (Hunter,

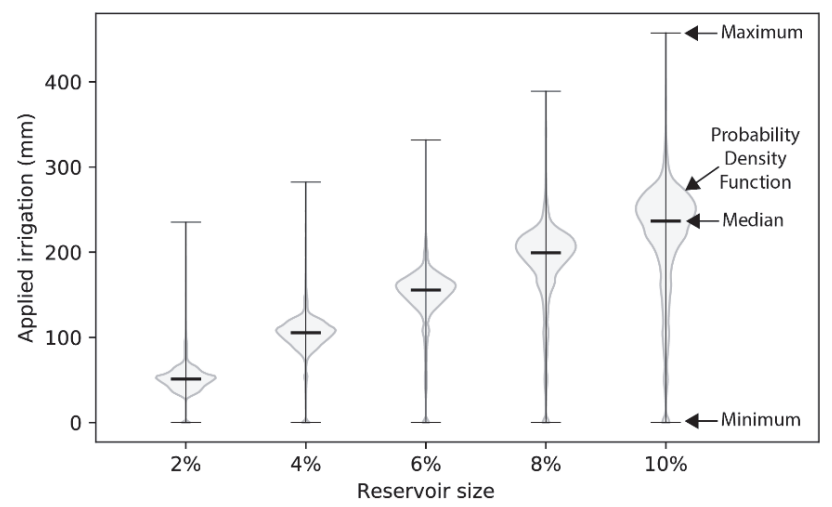

(a)

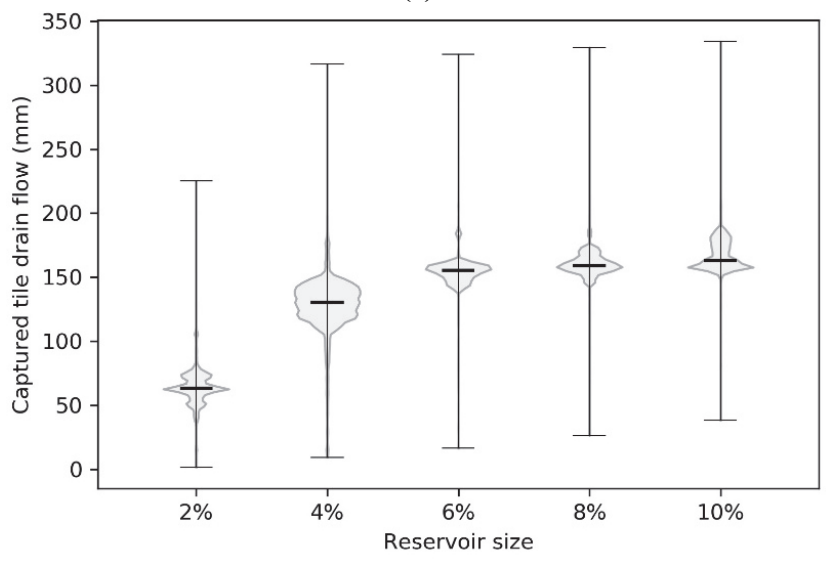

(b)

Figure 2. Violin plots of simulated (a) annual applied irrigation and (b) captured tile drain flow across the input parameter space. Reservoir size is expressed as a percentage of the irrigated field area with an average depth of $3.05 \mathrm{~m}$.
2007) in Python 3.7, with the probability density function estimated using a Gaussian kernel with a bandwidth determined by Scott's rule (Scott, 2015). The overall mean and standard deviations of the applied irrigation and captured tile drain flow outputs for each reservoir size are provided in table 4.

As shown in figure 2, a wide range of model output values may be achieved depending on input parameter selection. However, the rather narrow probability density functions suggest that the practical influence of uncertainty in input parameter values is low even for the most influential input parameters. The standard deviation of estimates for applied irrigation increased steadily across each reservoir size evaluated, while estimates for captured tile drain flow increased to a certain point (reservoir size of $6 \%$ ) before leveling out (table 4).

The median annual applied irrigation varied from $51 \mathrm{~mm}$ at a reservoir size representing $2 \%$ of the irrigated field area to $236 \mathrm{~mm}$ at a reservoir size of $10 \%$ (fig. 2a). While the majority of applied irrigation estimates were centered around the median, an additional clustering of points occurred around zero for all reservoir sizes. Because water inflows to the reservoir (i.e., precipitation, tile drain flow) were not varied in the sensitivity analysis, this indicates that there are certain input parameter conditions that either lead to large water losses from the reservoir (e.g., high rate of reservoir seepage), thereby limiting water availability for irrigation, or reductions in the crop irrigation requirement (e.g., low crop coefficients, high water depletion fraction, large soil water control volume) resulting in little to no demand for irrigation.

The median annual captured tile drain flow varied from $63 \mathrm{~mm}$ at a reservoir size of $2 \%$ to $163 \mathrm{~mm}$ at a reservoir size of $10 \%$ (fig. 2b). The distribution of captured tile drain flow estimates experienced the largest shift as reservoir size increased from $2 \%$ to $4 \%$. Unlike the results for applied irrigation, there were only minor differences in the distribution of captured tile drain flow estimates between reservoir sizes of $6 \%, 8 \%$, and $10 \%$. This was due to instances in which the stored water volume provided by large reservoir sizes often exceeded the total irrigation requirements, and without irrigation withdrawals reducing reservoir water volumes there was little opportunity to create additional water storage capacity even as potential reservoir storage capacity increased.

\section{SENSITIVITY OF APPLIED IRRIGATION AND CAPTURED TILE DRAIN FLOW}

The sensitivity analysis showed that the most influential parameter for both model outputs was the soil water control volume ( $s w c v)$, which is defined in the model based on the average tile drain depth. In this analysis, the sensitivity to

Table 4. Overall means and standard deviations (in parentheses) for the model outputs, applied irrigation and captured tile drain flow.

\begin{tabular}{cccccc}
\hline & \multicolumn{5}{c}{ Reservoir Size } \\
\cline { 2 - 6 } Model Output & $2 \%$ & $4 \%$ & $6 \%$ & $8 \%$ & $10 \%$ \\
\hline Applied irrigation & 51.6 & 103.3 & 149.3 & 187.6 & 219.3 \\
$(\mathrm{~mm})$ & $(16.7)$ & $(24.0)$ & $(35.0)$ & $(48.6)$ & $(63.5)$ \\
\hline Captured tile drain flow & 64.4 & 128.7 & 152.7 & 159.6 & 166.6 \\
$(\mathrm{~mm})$ & $(16.4)$ & $(23.7)$ & $(20.8)$ & $(18.5)$ & $(18.3)$ \\
\hline
\end{tabular}


$s w c v$ represents the sensitivity to total plant-available water in the soil water balance, which also depends on the volumetric water contents at field capacity and wilting point. First-order sensitivity for $s w c v$ varied between 0.21 and 0.28 for applied irrigation and between 0.14 and 0.30 for captured tile drain flow across all reservoir sizes (figs. 3 and 4). Incorporating interaction effects with other input parameters, the total-order sensitivity of $s w c v$ was 0.48 to 0.66 for applied irrigation and 0.50 to 0.64 for captured tile drain flow across all reservoir sizes. As reservoir size increased, the total-order sensitivity of $s w c v$ decreased steadily for applied irrigation but showed no consistent pattern in regard to captured tile drain flow. Results for each reservoir size are provided as supplementary material (available at https://doi.org/10.6084/m9.figshare.11639679).

Changes to total available water, through uncertainty in any of the physical components defining it (e.g., average tile drain depth defining $s w c v$, field capacity water content, wilting point water content), play a central role in the soil water balance within the model and have a cascading effect through the DWR system, thereby influencing both applied irrigation and captured tile drain flow outputs. Within the context of the model, if total available water is underestimated, then soil water deficit conditions would be expected to occur earlier in the growing season and be of greater magnitude than actual field conditions because potential evapotranspiration would exceed available water within the soil profile. This would lead to a greater demand for irrigation from the reservoir. Subsequently, the increased use of water from the reservoir for irrigation would create additional water storage capacity for capturing tile drain flow during or after the growing season. These results are consistent with those of other researchers who have found that total available water is highly influential in estimating actual evapotranspiration because of the importance of total available water in the soil water balance, which determines if water is available to evapotranspire (DeJonge et al., 2012; Zhao et al., 2015).

The input value for the water depletion fraction ( $p$ fract) becomes important within the model because it serves as the threshold for initiating irrigation by setting the amount of water that can be depleted before deficit water stress occurs. The water depletion fraction was the second most sensitive input parameter for applied irrigation $\left(S=0.05\right.$ to $0.10, S_{T}=$ 0.21 to 0.34 ) and the third most sensitive input parameter for captured tile drain flow ( $S=0.03$ to $0.07, S_{T}=0.26$ to 0.34 ) when averaged across all reservoir sizes. The total-order sensitivity of pfract decreased with increasing reservoir size for the applied irrigation output but showed no pattern with increasing reservoir size for captured tile drain flow.

Given low input values for pfract, the timing of irrigation is expected to occur earlier in the growing season, and the frequency of irrigation throughout the gro.wing season is expected to increase because less water is required to be depleted from the soil profile before the onset of deficit water stress. With a greater demand for irrigation, applied irrigation amounts would increase, resulting in reduced reservoir water level and a greater capacity for capturing tile drain
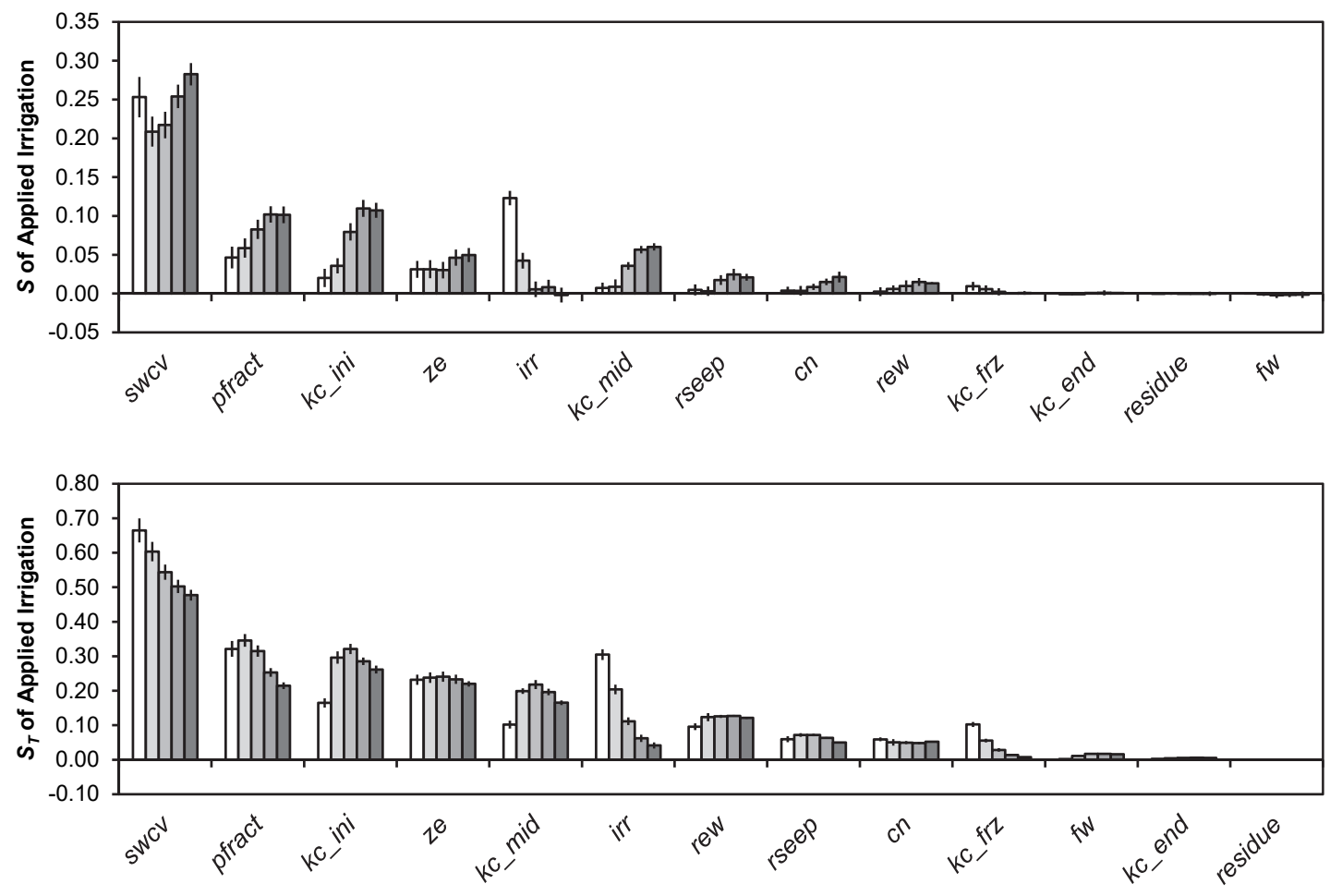

Figure 3. First-order $(S)$ and total-order $\left(S_{T}\right)$ sensitivity of applied irrigation to input parameters: $s w c v=$ soil water control volume, pfract= water depletion fraction, $r s e e p=$ rate of reservoir seepage, $k c \_i n i=$ crop coefficient for initial crop period, $k c \_m i d=$ crop coefficient for mid-season crop period, $k c_{-} e n d=$ crop coefficient for end of crop period, $k c \_f r z=$ crop coefficient for frozen conditions, $z e=$ depth of soil evaporation zone, $r e w$ $=$ readily evaporable water, $i r r=$ irrigation application depth, $\boldsymbol{c n}=$ curve number, fw $=$ fraction of wetted surface, and residue $=$ non-growing season residue amount. Reservoir size: $\square=2 \%, \square=4 \%, \square=6 \%, \square=8 \%, \square=10 \%$. Bars include $95 \%$ confidence intervals. 

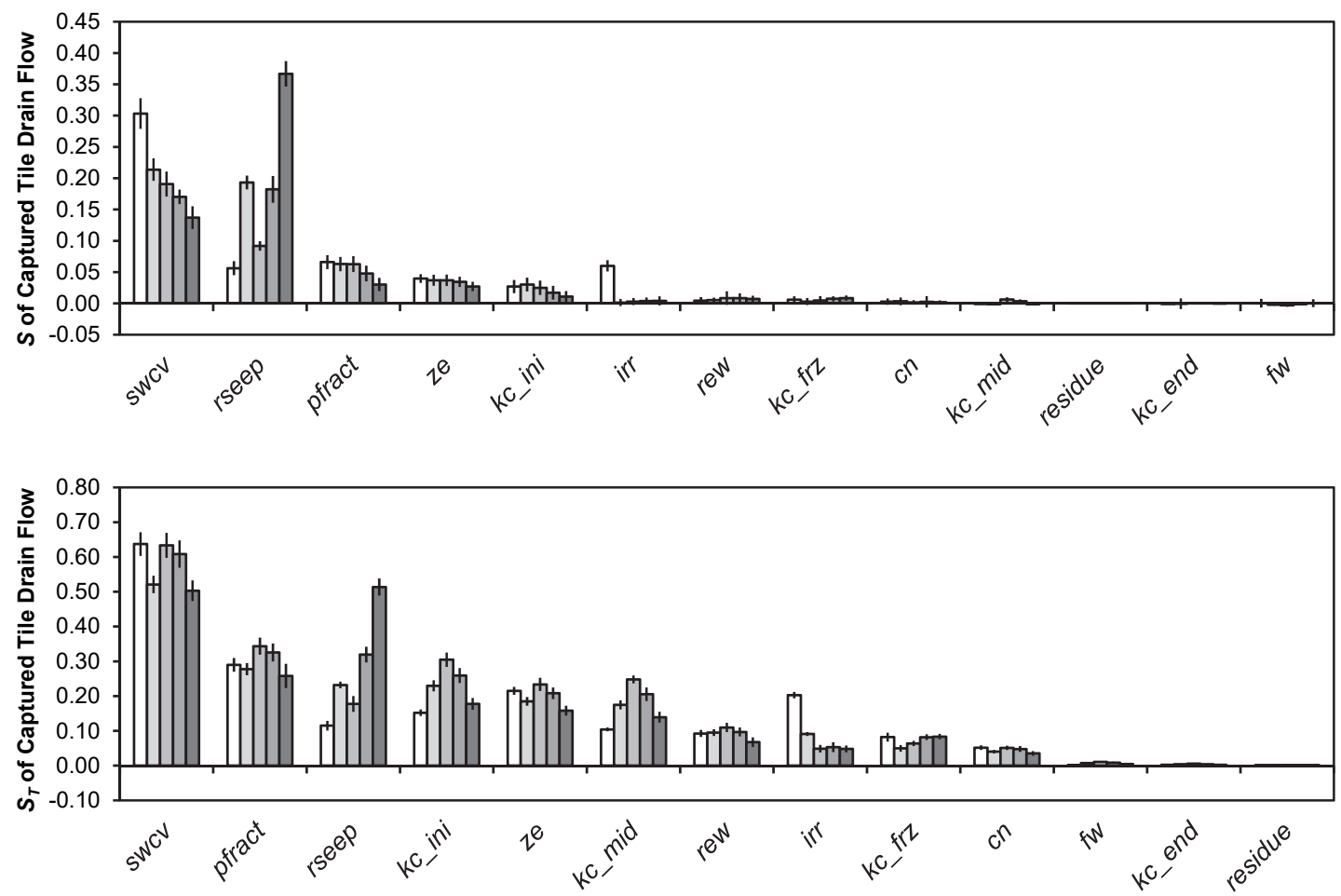

Figure 4. First-order $(S)$ and total-order $\left(S_{T}\right)$ sensitivity of captured tile drain flow to input parameters: $s w c v=$ soil water control volume, $p f r a c t$ $=$ water depletion fraction, $r$ seep $=$ rate of reservoir seepage, $k c_{-} i n i=$ crop coefficient for initial crop period, $k c_{-}$mid $=$crop coefficient for midseason crop period, $k c_{-} e n d=$ crop coefficient for end of crop period, $k c_{-} f r z=$ crop coefficient for frozen conditions, $z e=$ depth of soil evaporation zone, $r e w=$ readily evaporable water, $i r r=$ irrigation application depth, $c n=$ curve number, $f w=$ fraction of wetted surface, and residue $=$ nongrowing season residue amount. Reservoir size: $\square=2 \%, \square=4 \%, \square=6 \%, \square=8 \%, \square=10 \%$. Bars include $95 \%$ confidence intervals.

flow. The resulting effect on model output is similar to underestimating the amount of total available water, as both would result in a greater and more frequent occurrence of simulated deficit water stress.

The rate of reservoir seepage (rseep), which influences the amount of water lost each day from the reservoir due to seepage into surrounding soils, was influential in impacting captured tile drain flow but had a lesser impact on applied irrigation. This difference in sensitivity of the two model outputs may be explained by two factors related to timing, which may vary among years. First, seepage losses from the reservoir will not change the amount of water withdrawn for irrigation unless water availability in the reservoir also becomes limiting, such as at small reservoir sizes or high total irrigation requirements. However, seepage losses will always create additional capacity within the reservoir to capture and store subsequent tile drain flow regardless of water availability. The second factor is that the influence of seepage on irrigation depends on the average time between irrigation events, usually days or weeks, while its influence on captured tile flow depends on the time between the last irrigation event and the first major drain flow event, which may be weeks or months. Therefore, seepage losses have a greater length of time to accumulate and influence captured tile drain flow.

The crop coefficients describe the amount of evapotranspiration occurring within the field throughout the year in relation to a grass-based reference crop. Of the four crop co- efficient inputs evaluated, the coefficients applicable to initial crop establishment $\left(k c_{-} i n i\right)$ and the mid-season crop growth period $\left(k c \_\right.$mid $)$were the most sensitive. The effect of increasing $k c_{-}$in $i$ and $k c_{-}$mid is to increase crop evapotranspiration, resulting in irrigation applications earlier in the growing season and of greater magnitude, but also a greater potential for the capture of tile drain flow during the growing season because reservoir water levels are reduced to meet irrigation requirements. The crop coefficient for initial establishment showed first-order sensitivities of 0.02 to 0.11 for applied irrigation but only 0.01 to 0.03 for captured tile drain flow, while total-order sensitivity was notably higher ( $S_{T}=0.16$ to 0.32 for applied irrigation, and $S_{T}=0.15$ to 0.30 for captured tile drain flow). The mid-season crop coefficient also showed low first-order sensitivity $(S \leq 0.01)$ but indicated interaction effects for both model outputs, with total order-sensitivities varying from 0.10 to 0.25 . This showed that for $k c$ ini and $k c \_m i d$, the majority of their influence on model outputs was linked to interaction with other input parameters. The crop coefficients for the end of crop growth $(k c$ end $)$ and periods of frozen conditions ( $k c$ frz) generally showed first-order sensitivities less than or equal to 0.01 for both model outputs, and based on totalorder sensitivities, both $k c_{\text {_end }}$ and $k c \_f r z$ fell below the 0.05 screening threshold, identifying these input parameters as low-sensitivity parameters.

Satti et al. (2004) and Linhoss et al. (2017) found similar results showing that changes in crop coefficients were influential in affecting irrigation estimates. This emphasizes the 
importance of using regionally developed crop coefficients in the estimation of crop evapotranspiration for specific crop varieties and climates. The most widely available resources for crop coefficients have largely been focused on arid to subhumid climates where irrigation has traditionally been required to support crop production, and specifically pertain to crops managed under stress-free conditions (Allen et al., 1998; Jensen and Allen, 2016). Application of these crop coefficient values outside of their original context can create sizeable errors in estimating crop evapotranspiration and subsequent irrigation demand (Jagtap and Jones, 1989).

The soil evaporation zone $(z e)$ describes the soil surface depth containing soil water that is subject to evaporation, and readily evaporable water (rew) describes the amount of soil water within the soil evaporation zone that can be freely evaporated without limitations by the physical or hydraulic properties of the soil. Given greater values for ze and rew, estimates of evaporative loss from the field will be greater, which when combined with estimates of transpiration that are based on chosen values for crop coefficients, can contribute to increased levels of evapotranspiration, greater amounts of water depletion from the soil water balance, and increased irrigation requirements. Individually, evaporationrelated input parameters including ze and rew exhibited low first-order sensitivity $(S \leq 0.05)$ for both model outputs and across all reservoir sizes. However, similar to the response shown by $k c$ _ini and $k c \_$mid, both ze and rew were involved in interaction effects with other parameters, and these effects were more pronounced for the applied irrigation output. The total-order sensitivity varied from 0.16 to 0.24 for $z e$ and from 0.07 to 0.13 for rew across all reservoir sizes. Interaction effects are likely greatest in combination with the $k c \_i n i$ and $k c \_$mid input parameters as, collectively, these parameters represent critical components of the dual-crop coefficient approach used by the model.

The amount of irrigation applied during each irrigation event is defined as the irrigation application depth (irr). Estimates of sensitivity for irr exhibited a negative relationship with reservoir size for both model outputs because small reservoir sizes provide less water availability for increasingly large irrigation withdrawal volumes. First-order and totalorder sensitivity values were greatest at a reservoir size of $2 \%$ for applied irrigation $\left(S=0.12, S_{T}=0.30\right)$ and captured tile drain flow $\left(S=0.06, S_{T}=0.20\right)$, but values fell to $\leq 0.05$ as reservoir size increased. This negative relationship was also apparent for swcv and pfract, which highlights their shared role in influencing the overall demand for irrigation. For example, small values for $s w c v$ (i.e., less total available water) or pfract (i.e., less tolerance to deficit water stress) result in increases in irrigation requirements, leading to greater amounts of applied irrigation, given an adequate water supply. Likewise, large values for irr (i.e., high-volume irrigation applications) require large volumes of water from the reservoir whenever irrigation is required, and these largevolume water requirements may quickly overwhelm smaller reservoirs. However, given a large enough reservoir size, the total amount of water stored may exceed the demand for irrigation regardless of the chosen values for swcv, pfract, or irr, resulting in lower sensitivity values for the applied irrigation output at large reservoir sizes.

Curve number $(c n)$, fraction of wetted surface $(f w)$, which describes the fraction of the soil surface wetted by rain and irrigation, and the non-growing season residue amount (residue), which describes the average fraction of the soil surface covered by crop residue, were identified as low-sensitivity parameters with average total-order sensitivity values less than or equal to the screening threshold (0.05) for both model outputs across all reservoir sizes.

\section{ONLINE TOOL}

Results from the sensitivity analysis were used to guide the development of the user interface for EDWRD. Each of the input parameters showing average total-order sensitivity values above the screening threshold were incorporated into the user interface (table 5). This ensures that user interaction is focused on the most influential input parameters and gives users the opportunity to represent specific site conditions within the model.

The low-sensitivity input parameters $(k c f r z, c n, f w$, $k c \_$end, and residue) are not directly included as part of the user interface, given the minimal influence they have on model outputs. Instead, default values are assigned within the source code. This reduces the number of input parameter selections that must be made by the user with little risk of impacting the final model outputs by selections that may not exactly match the site conditions. However, advanced users are provided the functionality for uploading their own sitespecific values as part of a custom input parameter file

Table 5. Input parameter total-order sensitivity $\left(S_{T}\right)$ for applied irrigation and captured tile drain flow across a range of reservoir sizes.

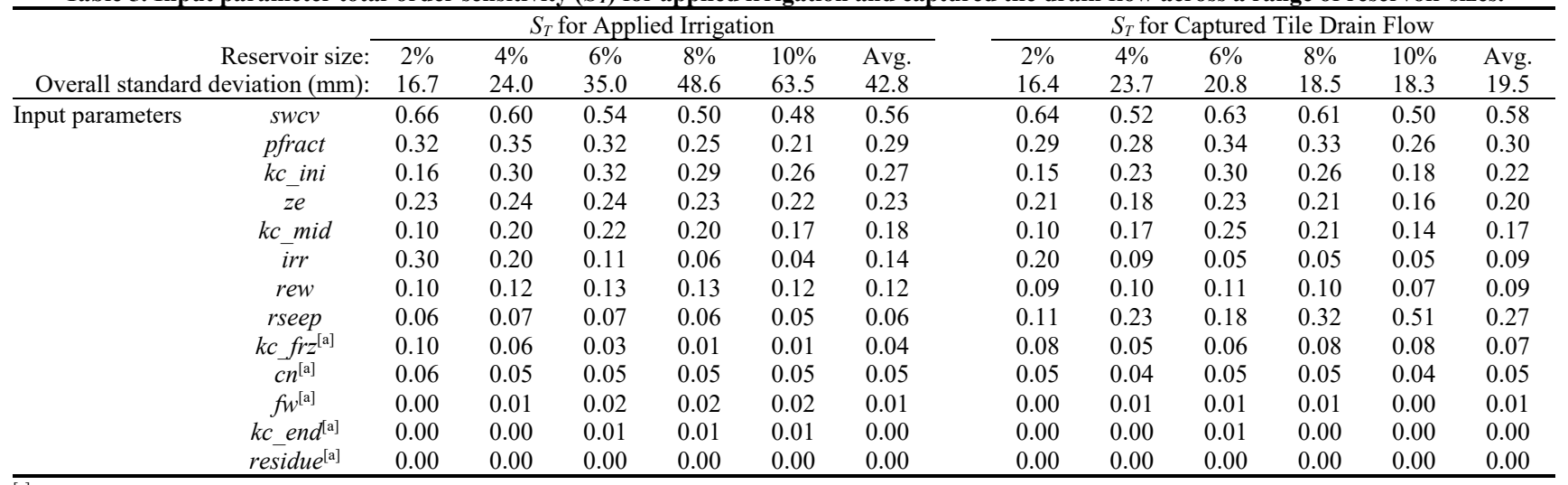

[a] Low-sensitivity input parameters, average $S_{T} \leq 0.05$ screening threshold. 
upload. This allows advanced users who wish to model highly specific scenarios to control the entire input parameter space for the model while maintaining a simplified user interface for more basic users.

EDWRD includes internal checks and message interaction with the user to ensure validity in daily time-series data, input parameters, and outputs (fig. 5). This integrated checking functionality serves as a benefit to users in preparing and testing time-series data and input parameter selections, evaluating results, and communicating errors or suggesting tool improvements to tool developers.

For all inputs, default values are provided to represent typical soil and weather conditions in the U.S. Midwest and assign values to low-sensitivity inputs that are not included directly in the user interface. Users can identify separate areas to represent the drainage area contributing to the reservoir and the irrigated field area. Precompiled time-series datasets are also available for several research sites across the region as part of the USDA-NIFA-funded Transforming Drainage Project (Reinhart et al., 2016). This approach also provides a simple method for users to generate initial estimates with EDWRD for the purpose of learning more about DWR systems and their potential benefits. Options are also available to allow users to upload their own time-series data files. Model outputs are presented to the user directly on the screen through a series of interactive visualizations and can also be downloaded.

\section{Conclusions}

This article introduces an open-source modeling framework that combines water balances for a tiledrained field and water storage reservoir to simulate the potential benefits of drainage water recycling (DWR) systems, a novel practice providing irrigation and water quality benefits in tile-drained agricultural landscapes. A sensitivity analysis of 13 model input parameters showed that parameters controlling the total available water of the soil profile and total evaporable DWR systems. Other influential parameters for determining water from the soil surface were the most influential in estimating the potential irrigation and water quality benefits of irrigation and water quality benefits were the water depletion fraction, which describes how much of the available water in the soil profile may be depleted by evapotranspiration before the crop experiences deficit water stress, and crop coefficients for the growing season periods describing water use during initial crop establishment and mid-season development. Irrigation application depth was a sensitive input parameter for estimating the amount of applied irrigation, while the daily reservoir seepage rate was sensitive when estimating the amount of tile drain flow that can be captured by DWR systems. Model outputs were insensitive to changes in parameter values for curve number, fraction of wetted surface, crop coefficients for the end of crop growth and frozen soil conditions, and the non-growing season residue amount.

An online tool, Evaluating Drainage Water Recycling Decisions (EDWRD), was developed based on the modeling framework presented here. The user interface incorporates results from the sensitivity analysis and makes available pre-defined data files and default settings to develop a simple, accessible tool for a variety of potential users. Results of the potential irrigation and water quality benefits are displayed using interactive visualizations to help users evaluate DWR systems with various reservoir sizes and across multiple years. EDWRD is accessible via any standard web-browser at https://transformingdrainage.org/tools/edwrd, and the source code can be found at https://github.com/TransformingDrainageProject/edwrd.

\section{ACKNOWLEDGEMENTS}

This material is based on work that is supported by the USDA National Institute of Food and Agriculture under Award No. 2015-68007-23193, "Managing Water for Increased Resiliency of Drained Agricultural Land-

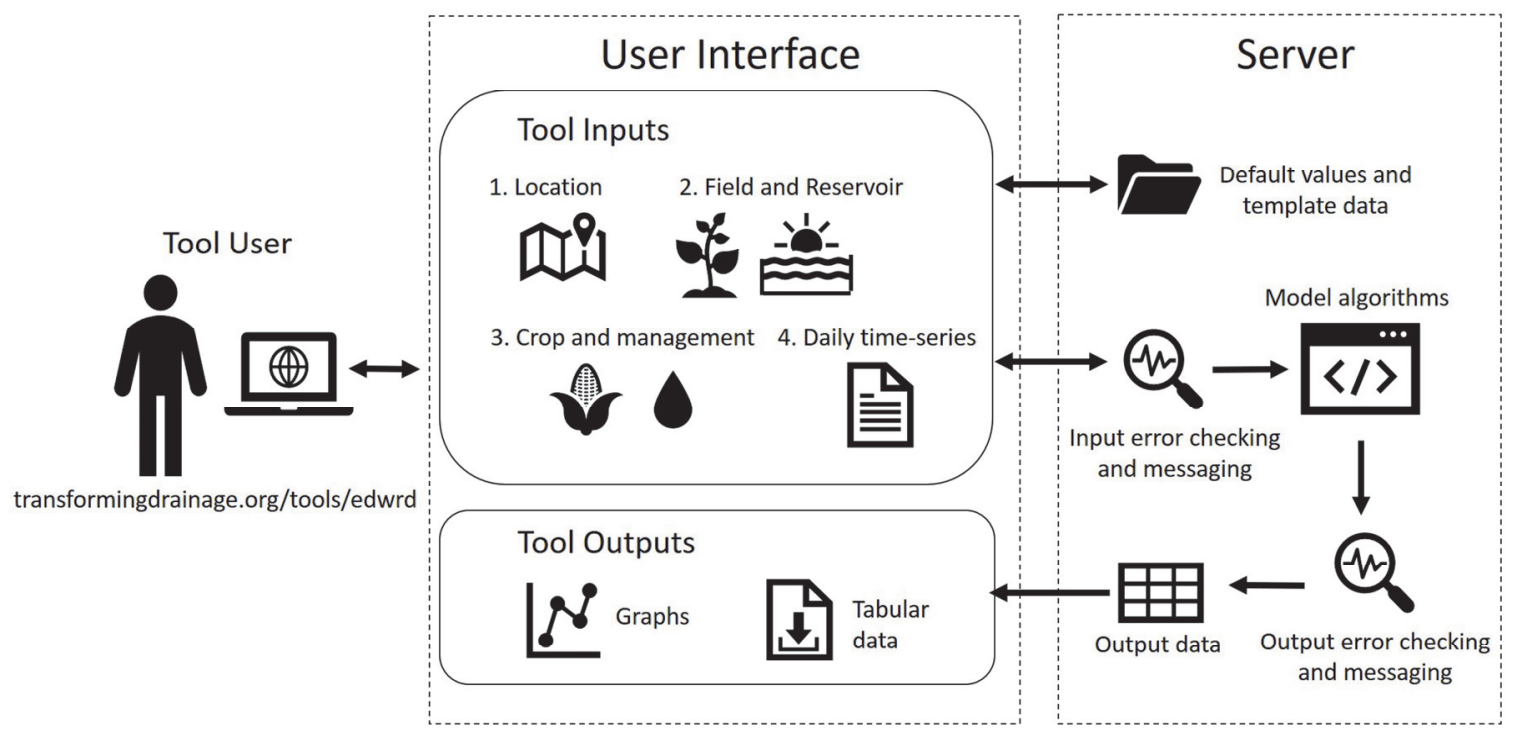

Figure 5. Schematic overview of Evaluating Drainage Water Recycling Decisions (EDWRD). 
scapes" (http://transformingdrainage.org). Supplementary material for this article can be found at https://doi.org/10.6084/m9.figshare.11639679.

\section{REFERENCES}

Abendroth, L. J., Herzmann, D. E., Chighladze, G., Kladivko, E. J., Helmers, M. J., Bowling, L., ... Villamil, M. B. (2017). Sustainable corn CAP research data (USDA-NIFA Award No. 2011-68002-30190). Washington, DC: USDA-ARS. http://dx.doi.org/10.15482/USDA.ADC/1411953

Allen, R. G., Pereira, L. S., Raes, D., \& Smith, M. (1998). Crop evapotranspiration: Guidelines for computing crop water requirements. Irrigation and Drainage Paper No. 56. Rome, Italy: United Nations FAO.

Allen, R. G., Wright, J. L., Pruitt, W. O., Pereira, L. S., \& Jensen, M. E. (2007). Chapter 8. Water requirements. In G. J. Hoffman, R. G. Evans, M. E. Jensen, D. L. Marting, \& R. L. Elliot (Eds.), Design and operation of farm irrigation system (2nd Ed., pp. 208-288). St. Joseph, MI: ASABE. https://doi.org/10.13031/2013.23691

Allred, B. J., Gamble, D. L., Clevenger, W. B., LaBarge, G. A., Prill, G. L., Czartoski, B. J., ... Brown, L. C. (2014a). Crop yield summary for three wetland reservoir subirrigation systems in northwest Ohio. Appl. Eng. Agric., 30(6), 889-903. https://doi.org/10.13031/aea.30.10501

Allred, B. J., Gamble, D. L., Levison, P. W., Scarborough, R. L., Brown, L. C., \& Fausey, N. R. (2014b). Field test results for nitrogen removal by the constructed wetland component of an agricultural water recycling system. Appl. Eng. Agric., 30(2), 163-177. https://doi.org/10.13031/aea.30.10061

Andersen, D. S., Burns, R. T., Moody, L. B., Helmers, M. J., Horton, R., \& Pederson, C. (2010). Use of the soil-plant-airwater model to predict hydraulic performance of vegetative treatment areas controlling open lot runoff. Trans. ASABE, 53(2), 537-543. https://doi.org/10.13031/2013.29568

Arnold, J. G., \& Stockle, C. O. (1991). Simulation of supplemental irrigation from on-farm ponds. J. Irrig. Drain. Eng., 117(3), 408-424. https://doi.org/10.1061/(ASCE)07339437(1991)117:3(408)

Biehl, L. L., Zhao, L., Song, C. X., \& Panza, C. G. (2017). Cyberinfrastructure for the collaborative development of $\mathrm{U} 2 \mathrm{U}$ decision support tools. Clim. Risk Mgmt., 15, 90-108. https://doi.org/10.1016/j.crm.2016.10.003

Cariboni, J., Gatelli, D., Liska, R., \& Saltelli, A. (2007). The role of sensitivity analysis in ecological modelling. Ecol. Model., 203(1), 167-182. https://doi.org/10.1016/j.ecolmodel.2005.10.045

Christianson, L. E., \& Harmel, R. D. (2015). The MANAGE drain load database: Review and compilation of more than fifty years of North American drainage nutrient studies. Agric. Water Mgmt., 159, 277-289. https://doi.org/10.1016/j.agwat.2015.06.021

de Wit, A., Boogaard, H., Fumagalli, D., Janssen, S., Knapen, R., van Kraalingen, D., ... van Diepen, K. (2019). 25 years of the WOFOST cropping systems model. Agric. Syst., 168, 154-167. https://doi.org/10.1016/j.agsy.2018.06.018

DeJonge, K. C., Ascough II, J. C., Ahmadi, M., Andales, A. A., \& Arabi, M. (2012). Global sensitivity and uncertainty analysis of a dynamic agroecosystem model under different irrigation treatments. Ecol. Model., 231, 113-125.

https://doi.org/10.1016/j.ecolmodel.2012.01.024
Foster, T., Brozović, N., Butler, A. P., Neale, C. M., Raes, D., Steduto, P., ... Hsiao, T. C. (2017). AquaCrop-OS: An opensource version of FAO's crop water productivity model. Agric. Water Mgmt., 181, 18-22. https://doi.org/10.1016/j.agwat.2016.11.015

Frankenberger, J., Reinhart, B., Nelson, K., Bowling, L., Hay, C., Youssef, M., ... Allred, B. (2017). Questions and answers about drainage water recycling for the Midwest. ABE-156-W. West Lafayette, IN: Purdue University.

Haan, C. T., Storm, D. E., Al-Issa, T., Prabhu, S., Sabbagh, G. J., \& Edwards, D. R. (1998). Effect of parameter distributions on uncertainty analysis of hydrologic models. Trans. ASAE, 41(1), 65-70. https://doi.org/10.13031/2013.17158

Han, W., Yang, Z., Di, L., \& Mueller, R. (2012). CropScape: A web service based application for exploring and disseminating U.S. conterminous geospatial cropland data products for decision support. Comput. Electron. Agric., 84, 111-123. https://doi.org/10.1016/j.compag.2012.03.005

Hay, C. H., \& Irmak, S. (2009). Actual and reference evaporative losses and surface coefficients of a maize field during nongrowing (dormant) periods. J. Irrig. Drain. Eng., 135(3), 313-322. https://doi.org/10.1061/(ASCE)IR.1943-4774.0000001

Herman, J. D., \& Usher, W. (2017). SALib: An open-source Python library for sensitivity analysis. J. Open Source Softw., 2(9), 97. https://doi.org/10.21105/joss.00097

Hertzberger, A., Pittelkow, C. M., Harmel, R. D., \& Christianson, L. E. (2019). The MANAGE drain concentration database: A new tool compiling North American drainage nutrient concentrations. Agric. Water Mgmt., 216, 113-117. https://doi.org/10.1016/j.agwat.2019.01.021

Holzworth, D. P., Huth, N. I., deVoil, P. G., Zurcher, E. J., Herrmann, N. I., McLean, G., ... Keating, B. A. (2014). APSIM: Evolution toward a new generation of agricultural systems simulation. Environ. Model. Softw., 62, 327-350. https://doi.org/10.1016/j.envsoft.2014.07.009

Hunter, J. D. (2007). Matplotlib: A 2D graphics environment. Comput. Sci. Eng., 9(3), 90-95. https://doi.org/10.1109/MCSE.2007.55

Ince, D. C., Hatton, L., \& Graham-Cumming, J. (2012). The case for open computer programs. Nature, 482(7386), 485-488. https://doi.org/10.1038/nature10836

Jagtap, S. S., \& Jones, J. W. (1989). Stability of crop coefficients under different climate and irrigation management practices. Irrig. Sci., 10(3), 231-244. https://doi.org/10.1007/BF00257955

Jensen, M. E., \& Allen, R. G. (Eds.). (2016). Evaporation, evapotranspiration, and irrigation water requirements (2nd Ed.). Reston, VA: ASCE. https://doi.org/10.1061/9780784414057

Jones, J. W., Hoogenboom, G., Porter, C. H., Boote, K. J., Batchelor, W. D., Hunt, L. A., ... Ritchie, J. T. (2003). The DSSAT cropping system model. European J. Agron., 18(3-4), 235-265. https://doi.org/10.1016/S1161-0301(02)00107-7

Linhoss, A. C., Tagert, M. L., Buka, H., \& Sassenrath, G. (2017). Factors affecting model sensitivity and uncertainty: Application to an irrigation scheduler. Trans. ASABE, 60(3), 803-812. https://doi.org/10.13031/trans.11912

Malano, H. M., \& Burton, M. (2001). Guidelines for benchmarking performance in the irrigation and drainage sector. Rome, Italy: United Nations FAO.

Melvin, S. W., \& Kanwar, R. S. (1995). Environmental and economic impacts of a recycling subirrigation-drainage system. In H. W. Belcher \& F. M. D'Itri (Eds.), Subirrigation and controlled drainage (pp. 315-326). Boca Raton, FL: CRC Press. 
Millhollon, E. P., Rodrigue, P. B., Rabb, J. L., Martin, D. F., Anderson, R. A., \& Dans, D. R. (2009). Designing a constructed wetland for the detention of agricultural runoff for water quality improvement. J. Environ. Qual., 38(6), 2458-2467. https://doi.org/10.2134/jeq2008.0526

Muleta, M. K., \& Nicklow, J. W. (2005). Sensitivity and uncertainty analysis coupled with automatic calibration for a distributed watershed model. J. Hydrol., 306(1-4), 127-145. https://doi.org/10.1016/j.jhydrol.2004.09.005

Ouyang, Y., Feng, G., Leininger, T. D., Read, J., \& Jenkins, J. N. (2018). Pond and irrigation model (PIM): A tool for simultaneously evaluating pond water availability and crop irrigation demand. Water Resour. Mgmt., 32(9), 2969-2983. https://doi.org/10.1007/s11269-018-1967-8

Palmer, W. L., Barfield, B. J., \& Haan, C. T. (1982). Sizing farm reservoirs for supplemental irrigation of corn: Part I. Modeling reservoir size yield relationships. Trans. ASAE, 25(2), 372-376. https://doi.org/10.13031/2013.33538

Pianosi, F., Beven, K., Freer, J., Hall, J. W., Rougier, J., Stephenson, D. B., \& Wagener, T. (2016). Sensitivity analysis of environmental models: A systematic review with practical workflow. Environ. Model. Softw., 79, 214-232. https://doi.org/10.1016/j.envsoft.2016.02.008

Reinhart, B. D., Frankenberger, J. R., Hay, C. H., \& Helmers, M. J. (2019). Simulated water quality and irrigation benefits from drainage water recycling at two tile-drained sites in the U.S. Midwest. Agric. Water Mgmt., 223, 105699. https://doi.org/10.1016/j.agwat.2019.105699

Reinhart, B., Frankenberger, J., Abendroth, L., Ahiablame, L., Bowling, L., Brown, L., ... Youssef, M. (2016). Drainage water storage for improved resiliency and environmental performance of agricultural landscapes. ASABE Paper No. 162557416. St. Joseph, MI: ASABE. https://doi.org/10.13031/IDS.20162557416

Saadat, S., Bowling, L., Frankenberger, J., \& Kladivko, E. (2018). Estimating drain flow from measured water table depth in layered soils under free and controlled drainage. J. Hydrol., 556, 339-348. https://doi.org/10.1016/j.jhydrol.2017.11.001

Saltelli, A. (2002). Making best use of model evaluations to compute sensitivity indices. Comput. Phys. Comm., 145(2), 280297. https://doi.org/10.1016/S0010-4655(02)00280-1

Saltelli, A., Ratto, M., Andres, T., Campolongo, F., Cariboni, J., Gatelli, D., ... Tarantola, S. (2008). Global sensitivity analysis: The primer. Hoboken, NJ: John Wiley \& Sons. https://doi.org/10.1002/9780470725184

Sarrazin, F., Pianosi, F., \& Wagener, T. (2016). Global sensitivity analysis of environmental models: Convergence and validation. Environ. Model. Softw., 79, 135-152. https://doi.org/10.1016/j.envsoft.2016.02.005
Satti, S. R., Jacobs, J. M., \& Irmak, S. (2004). Agricultural water management in a humid region: Sensitivity to climate, soil, and crop parameters. Agric. Water Mgmt., 70(1), 51-65. https://doi.org/10.1016/j.agwat.2004.05.004

Saxton, K. E., \& Willey, P. H. (2005). The SPAW model for agricultural field and pond hydrologic simulation. In V. P. Sing \& D. K. Frevert (Eds.), Watershed models (pp. 400-435). Boca Raton, FL: CRC Press.

Scott, D. W. (2015). Multivariate density estimation: Theory, practice, and visualization. Hoboken, NJ: John Wiley \& Sons. https://doi.org/10.1002/9781118575574

Skaggs, R. W., Youssef, M. A., \& Chescheir, G. M. (2012). DRAINMOD: Model use, calibration, and validation. Trans. ASABE , 55(4), 1509-1522. https://doi.org/10.13031/2013.42259

Sobol, I. M. (2001). Global sensitivity indices for nonlinear mathematical models and their Monte Carlo estimates. Math. Comput. Simul., 55(1), 271-280. https://doi.org/10.1016/S03784754(00)00270-6

Stuff, R. G., \& Dale, R. F. (1978). A soil moisture budget model accounting for shallow water table influences. SSSA J., 42(4), 637-643. https://doi.org/10.2136/sssaj1978.03615995004200040021x

Tan, C. S., \& Zhang, T. Q. (2011). Surface runoff and subsurface drainage phosphorus losses under regular free drainage and controlled drainage with sub-irrigation systems in southern Ontario. Canadian J. Soil Sci., 91(3), 349-359. https://doi.org/10.4141/cjss09086

Tan, C. S., Zhang, T. Q., Drury, C. F., Reynolds, W. D., Oloya, T., \& Gaynor, J. D. (2007). Water quality and crop production improvement using a wetland-reservoir and draining/subsurface irrigation system. Canadian Water Resour. J., 32(2), 129-136. https://doi.org/10.4296/cwrj3202129

USDA-NRCS. (2004). Chapter 9: Hydrologic soil-cover complexes. In National engineering handbook: Part 630 Hydrology. Washington, DC: USDA-NRCS.

USDA-NRCS. (2009). Appendix 10D: Design and construction guidelines for waste impoundments lined with clay or amendment-treated soil. In Agricultural waste management field handbook: Part 651. Washington, DC: USDA-NRCS.

Zhao, P., Li, S., Li, F., Du, T., Tong, L., \& Kang, S. (2015). Comparison of dual crop coefficient method and ShuttleworthWallace model in evapotranspiration partitioning in a vineyard of northwest China. Agric. Water Mgmt., 160, 41-56. https://doi.org/10.1016/j.agwat.2015.06.026 